Behavior and Social Issues, 21, 1-4 (2012). (C) Mark A. Mattaini. Readers of this article may copy it without the copyright owner's permission, if the author and publisher are acknowledged in the copy and the copy is used for educational, not-for-profit purposes. doi: 10.5210/bsi.v21i0.4346

\title{
Guns: The Data Tell Us ...
}

... not so much. As this is written, concern with firearm violence in the US is very high, following the elementary school shootings in Newtown, Connecticut in mid-December, 2012. The dialogue is loud and highly conflicted, and has moved beyond attention to the very rare mass shootings (likely to be quite difficult to impact) toward firearm violence overall in our society. President Barack Obama recently outlined a program of possible steps that might be taken both administratively and legislatively, including renewing the "assault weapons" ban, improved background checks for gun purchases, increased security in schools (an area of some agreement with the National Rifle Association [NRA] although both might deny it), attention to mental health services for vulnerable youth and young adults, and many others. Public positions taken by concerned stakeholders and policy makers have been controversial and in some cases extreme.

This situation begs the question of whether science, including behavior science can offer any real guidance; this question, however, is much more difficult to answer than it might seem, given the weakness of available data. A 2003 analysis by the Centers for Disease Control and Prevention (CDC) of 51 studies of firearms laws concluded that as of that time, there was insufficient evidence to determine effectiveness of any of them (Hahn et al., 2003). The CDC has not been funded to study gun violence for over a decade for political reasons. Although there have been many studies related to the impact of media on aggressive behavior, there have been few related to actual violence; worse yet, recent meta-analyses indicate that publication bias and weak measures may account for the relationships previously reported (Ferguson \& Kilburn, 2009; Savage \& Yancey, 2008). A few relatively weak studies have suggested that concealed carry laws reduce violence, a few other relatively weak studies suggest the opposite; overall it appears that the effect is negligible either way. Texas data indicate that those with carry permits commit crimes at about a 10 times lower rate than the average, but only persons with clean legal records are eligible, and generally only persons with some financial resources apply-low risk groups (for data over time, see Texas Department of Public Safety, 2013). This is therefore not an obvious area for emphasis, although it may challenge values for some.

What data there are, are commonly distorted by those on each of the multiple sides of the questions, often accompanied by statements about how statistics can 
be made to lie. The relative risks and benefits of keeping firearms in homes is a dramatic example; given the strongly held positions of some conducting the studies, sorting such questions out is currently challenging. Even the question of how dangerous it is to live in the US is controversial. Some-falsely-insist that the levels of violent crime are getting worse (they have dropped dramatically over the past 20 years). Others look at an annual rate of victimization of 2-3 percent, and assert that risks are low. Lifetime levels, however, are much higher. A Department of Justice study done in 1987 (and apparently never since repeated ) estimated that a 12-year-old at that time faced an $83 \%$ chance of violent victimization over a lifetime (Koppel, 1987). Estimates would likely be somewhat lower now, but we simply don't know, given the paucity of research.

Apparently simple solutions often are not. At the moment, there appears to be near universal political agreement on the potential value of enhanced background checks for firearms purchases, for example. How to word a law in such a way as to identify those with mental health issues who should not have access to guns without stigmatizing mental illness has proved difficult however, records are incomplete, and a majority of states do not regularly report such data. At the same time, the prediction of violence remains a very inexact science. In terms of criminal background, Duke University's Philip Cook recently reported on National Public Radio that his data show that even if criminal justice records were complete, they would fail to identify many who will commit homicides. There are similar complications with other policy proposals currently under consideration. Perhaps the only sure thing at present is that gun-buster signs are unlikely to deter mass murderers (or other armed criminals) from entering movie theaters, malls, or schools - although posting such signs is currently a common step.

Given all these challenges, is there a possible contribution that behavior analysis might make to the reduction of gun violence? We've done very little direct work so far, with the important exception of Ray Miltenberger's work teaching children safety skills to prevent gun play (e.g., Miltenberger, Flessner, Gatheridge, Johnson, Satterlund, \& Egerno, 2004). Miltenberger's work is demonstrably more effective than the NRA's widely implemented Eddie Eagle program, but of course is not nearly so well known. It is conceptually probable that violence and bullying prevention programs may in the long run reduce the risk of gun violence, but such reductions have not been established.

Two additional areas in which behavior analysts and behavioral systems analysts might contribute come immediately to mind. Behavior analysts in the prevention science world bring special skills, particularly in adapting interrupted time-series designs to community efforts (Biglan, Ary, \& Wagenaar, 2000). Some 
behavior analysts' commitment to a natural science approach and mindfulness about the risks of bias through an understanding of relational responding might be helpful in maintaining a scientifically neutral approach to design and data analysis in such studies. A key test will be whether behavior scientists celebrate findings contrary to their expectations, as did Erica Chenoweth, an acknowledged "guns and bombs" political scientist, whose data unexpectedly and incontrovertibly informed her that nonviolent resistance is at least twice as effective as violent alternatives (Chenoweth \& Stephan, 2011).

Firearms are obviously operanda for gun violence, but if nothing else behavior analysts understand that behavior is determined by more than such tools. (And there are hundreds of millions of such operanda in circulation.) Key in this case will be rigorous attentions to establishing operations. In particular, explorations of the relational responding present in current debates may suggest methods to achieve shifts in relational networks and bring higher levels of mindfulness to policy questions.

Guns. The NRA. The Right to Keep and Bear Arms (and "Second Amendment Solutions"). The Brady Campaign. Assault Weapons. Gun Registration. Sandy Hook. These words and many others participate in apparently irreconcilable relational networks that structure and are structured by extended verbal communities for many in our society. In the instance of firearms policies, those contextually constructed networks have in many cases become extraordinarily rigid (e.g., viewing the second amendment as God-given), nonoverlapping (the "two cultures"), and largely self-maintaining. Claims of openness to other points of view often appear to be no more than tactical (as in cases of politicians who currently state that they are "supporters of the second amendment" but have an extensive history of saying the opposite in other contexts, or those on the other side who claim to support strengthening background checks, but find fatal fault with every proposal to do so). To make things more challenging, as Hayes noted with regard to terrorism some years ago, "verbal/cognitive networks once formed tend to maintain themselves; and ... many of the things human beings do to change or eliminate undesirable verbal categorical processes are either inert or prone to making these processes more resistant to change" (Hayes, Niccolls, Masuda, \& Rye, 2002, p. 296).

So the challenge ... can behavior analysts mindfully pursue research that might help reorganize rigid relational responding and thus help us find and achieve support for new and more effective protections for human life? Some of those approaches may relate primarily to firearms, but I suspect real change may 


\title{
MATTAINI
}

need to go much more deeply into a culture of self-interest, consumerism, coercion and fear. ${ }^{1}$

\author{
Mark A. Mattaini \\ Jane Addams College of Social Work \\ University of Illinois at Chicago
}

\section{References}

Biglan, A., Ary, D., \& Wagenaar, A. C. (2000). The value of interrupted time-series experiments for community intervention research. Prevention Science, I, 31-49.

Chenoweth, E., \& Stephan, M. J. (2011). Why civil resistance works: The strategic logic of nonviolent conflict. New York: Columbia University Press.

Ferguson, C. J., \& Kilburn, J. (2009). The public health risks of media violence: A meta-analytic review. Journal of Pediatrics, 154, 759-763.

Hahn, R. A., Bilukha, O. O., Crosby, A., Fullilove, M. T., Liberman, A., Moscicki, E. K, ...Briss, P. (2003). First reports evaluating the effectiveness of strategies for preventing violence: Firearms laws. Atlanta, GA: Centers for Disease Control and Prevention. Retrieved from http://www.cdc.gov/MMWR/preview/mmwrhtml/rr5214a2.htm

Hayes, S. C., Niccolls, R., Masuda, A., \& Rye, A. K. (2002). Prejudice, terrorism, and behavior therapy. Cognitive and Behavioral Practice, 9, 296-301.

Koppel, H. (1987). Lifetime likelihood of victimization. Washington, DC: Bureau Justice Statistics, US Department of Justice, Technical Report NCJ-104274. Retrieved from https://www.ncjrs.gov/pdffiles1/bjs/104274.pdf

Miltenberger, R., Flessner, C., Gatheridge, B., Johnson, B., Satterlund, M., \& Egemo, K. (2004). Evaluation of behavioral skills training to prevent gun play in children. Journal of Applied Behavior Analysis, 37, 513-516.

Savage, J., \&Yancey, C. (2008). The effects of media violence exposure on criminal aggression: A meta-analysis. Criminal Justice and Behavior, 35, 772-791.

Texas Department of Public Safety (2013). Conviction Rates. Retrieved from http://www.txdps.state.tx.us/rsd/chl/reports/convrates.htm

\footnotetext{
${ }^{1}$ I emphasize mindfulness here because each of us likely comes to these question with our own well-established relational networks supported by our own verbal communities; I suspect the scholarship needed will require loosening such networks. The author has spent considerable time with several significantly incompatible verbal communities relevant to this discussion, and has striven to be mindful of his own relational responding here while advocating for objective, rigorous research - the reader will need to determine for herself the extent to which he has succeeded.
} 